九州大学学術情報リポジトリ

Kyushu University Institutional Repository

\title{
Removal of dissolved estrogen in sewage effluents by $\beta$-cyclodextrin polymer
}

Oishi, Kyoko

Department of Civil Engineering, Graduate School of Engineering, Kyushu University

Moriuchi, Ayumi

Fukuoka City Goverment

http://hdl. hand le. net/2324/26037

出版情報 : Science of the Total Environment. 409 (1)，pp.112-115，2010-12-01. Elsevier バージョン:

権利関係: (C) 2010 Elsevier B.V. 
Removal of dissolved estrogen in sewage effluents by $\beta$-cyclodextrin polymer

Kyoko Oishi ${ }^{\text {a. } *}$, Ayumi Moriuchi ${ }^{\text {b }}$

${ }^{a}$ Department of Civil Engineering, Graduate School of Engineering, Kyushu University, Motooka 744, Nishi-ku, Fukuoka 819-0395, Japan

${ }^{\mathrm{b}}$ Fukuoka City Goverment,1-8-1 Tenjin, Chuo-ku, Fukuoka 810-8620, Japan

${ }^{*}$ Corresponding author. Tel.:+81-92-802-3423; fax: +81-92-802-3423.

E-mail address: ohishi@civil.kyushu-u.ac.jp

Abstract

Substances with estrogenic activity are found in effluents of municipal sewage plants and dairy farms. These effluents have the potential to induce feminization in male fish. In this study, cyclodextrin polymers (CDPs) that are insoluble in both polar and nonpolar solvents were selected for the removal of dissolved estrogens in the effluent of a municipal sewage plant. The removal capacity of CDPs was high in the order of $\beta$-CDP $\geq \gamma$-CDP » $\alpha$-CDP. The mechanism for adsorption of estrogens to $\beta$-CDP was not only due to a host-guest interaction as molecular recognition by $\beta$-cyclodextrin $(\beta-C D)$, but also due to adsorption by the polymer matrix. $\beta$-CDP of $0.2 \%(\mathrm{w} / \mathrm{v})$ removed $17 \beta$-estradiol (E2) of about $70 \%$ from $10^{-11} \mathrm{~mol} / \mathrm{L}$, and more than $90 \%$ from $\geq 10^{-10} \mathrm{~mol} / \mathrm{L}$. The removal ratios of $\mathrm{E} 2$ in the presence of cholesterols, which are contained at higher concentrations than estrogens in sewage effluents and are adsorptive competitor for $\beta$-CDP, were about $85 \%$ at a cholesterol/E2 molar ratio of 100 and $>90 \%$ at molar ratios of $0.1,1$, and 10 . The effluent from a municipal sewage plant had estrogenic activity corresponding to $5.5 \times 10^{-11} \mathrm{~mol} \mathrm{E2/L}$ by yeast two-hybrid assay. The estrogens in the effluent were also removed $>90 \%$ by the $\beta$-CDP treatment. Therefore, $\beta$-CDP is able to remove dissolved estrogens over a wide range of concentrations in the presence of various contaminants such as wastewaters.

Keywords; endocrine disruption, estrogen, $\beta$-cyclodextrin polymer, sewage effluent, steroids removal

1. Introduction 
There is currently great interest in the contamination of steroid hormones such as natural estrogens and their synthetic analogs in natural aquatic environments (Hansen et al., 1998; Sarmah et al., 2006; Velicu and Suri, 2009). These compounds affect reproduction and development in wildlife at ng/L concentrations (Hansen et al., 1998; Jobling et al., 1998; Metcalfe et al., 2001; Miles-Richardson et al., 1999). Feminization of fish occurs from exposure to certain estrogens in concentrations as low as $10 \mathrm{ng} / \mathrm{L}$ (Kolodziej et al., 2004; Routledge et al., 1998). Velicu and Suri (2009) detected estrone (E1) and estriol (E3) in the environment at concentrations ranging from 0.6 to $2.6 \mathrm{ng} / \mathrm{L}$ and from 0.8 to $19 \mathrm{ng} / \mathrm{L}$, respectively. Metcalfe et al. (2001) observed the formation of ova in the testes of Japanese medaka (Oryzias latipes) starting at concentrations of $4 \mathrm{ng} / \mathrm{L}$ for $\mathrm{E} 2$, and $0.1 \mathrm{ng} / \mathrm{L}$ for 17a-ethynylestradiol (EE2). The major sources of E2 and EE2 in natural environments are thought to be municipal sewage and animal waste (Kömer et al., 2001; Panter et al., 1998; Sarmah et al., 2006; Shore and Shemesh, 2003). Desbrow et al. (1998) and Johnson et al.(2000) have also found natural and synthetic steroid estrogens such EE2 in the outlets of sewage treatment works. Snyder et al. (2001) also reported that natural estrogens and their synthetic analogues have been found in treated wastewater effluents. Furthermore, Chimchirian et al. (2007) found that the concentration of estrogens in the influent and effluent of three treatment plants ranged from 1.2 to $259 \mathrm{ng} / \mathrm{L}$ and 0.5 to $49 \mathrm{ng} / \mathrm{L}$, respectively. Rodgers-Gray et al. (2000) and Routledge et al. (1998) have also reported that hermaphroditic fish have been found downstream from a wastewater treatment plant. Most agricultural wastes have also been shown to contain high levels of estrogenic compounds (Desbrow et al., 1998; Hunag, and Sedlak, 2001; Kömer et al. 2001; Sarmah et al., 2006). Animal waste effluents especially contain large amounts of the compounds (Sarmah et al., 2006; Shore and Shemesh, 2003). These reports also show that certain surface waters can contain concentrations of estrogens that have the potential for endocrine disruption. 
Significant concentrations of estrogens in effluents have been attributed to their incomplete removal during the wastewater treatment process (Samir et al., 2006). In the degradation process, E2 is oxidized to E1 (Hanselman et al., 2003; Holbrook et al., 2002), and other estrogens are also degraded to simpler moieties, however EE2 is much more resistant to degradation than E2 (Jürgens et al., 2002). Therefore, the orders of detection frequency and concentration are E1, E3, 17a-estradiol, and E2 (Belfroid et al., 1999; Isobe et al., 2003; Velicu and Suri, 2009). The concentration of environmental estrogens discharged from sewage treatment plants are decreased by dilution, sorption, and degradation in the receiving ecosystem. Jürgens et al. (2002) reported that estradiols and E1 in stream water have half-lives of 0.1 and 11 days, respectively. Some of other estrogens can persist for a significant time in surface water. Therefore, it is important to remove chemically and physically steroid hormones in sewage treatment plants.

Oishi et al. (2008) showed that the estrogenic activity of E2 was suppressed by forming an inclusion complex with $\beta-C D$. However, this complex was not removed from waters because of the highly solubility. Recently, CDPs were produced by cross-linking CDs with epichlorohydrin (Kikuchi et al., 2005; Murai et al., 1998). They are insoluble in both polar and non-polar solvents. Therefore, they were applied for isolation or removal of specific compounds from a mixture (Murai et al., 1998; Kozlowski et al., 2005; Cathum et al., 2006). The effect of $\beta$-CDP on removal of dissolved estrogens from sewage effluents containing various contaminants was examined in this study.

\section{Materials and Methods}

\subsection{Materials}

$\alpha-, \beta-$, and $\gamma-C D P s$ were synthesized by Aomori Prefectural Industrial Technology Research 
Center (Local Independent Administrative Institution) in Aomori prefecture, Japan. The CDPs were prepared by crosslinking CDs with epichlorohydrin under alkali conditions (Kikuchi et al., 2005).

\subsection{Adsorptive property of CDPs to E2}

Each of $\alpha-, \beta-$, and $\gamma^{-C D P s}$ was added in a $10^{-4} \mathrm{molE} 2 / \mathrm{L}$ solution at $0.2 \%(\mathrm{w} / \mathrm{v})$. After $1 \mathrm{~h}$ incubation at room temperature, these solutions were centrifuged for $10 \mathrm{~min}$ at $3000 \mathrm{rpm}$. The UV spectra of the supernatants were measured with a spectrophotometer (Shimadzu, Japan).

\subsection{Adsorption capacity of $\beta$-CDP to E2}

$\beta$-CDP was added in $10^{-11}, 10^{-10}, 10^{-9}$, and $10^{-8}$ molE2/L at $0.2 \%(\mathrm{w} / \mathrm{v})$. Solutions of E2 without the added $\beta$-CDP were also prepared as references. After $1 \mathrm{~h}$ incubation at room temperature, the solutions were centrifuged for $10 \mathrm{~min}$ at $3000 \mathrm{rpm}$. The E2 concentration in the supernatant was measured with an E2 ELISA kit (Tokiwa Chemical Industries Co., Ltd., Tokyo, Japan), and the removal ratio of E2 from each solution was calculated by comparing the treated solution concentration to the reference.

2.4 Effect of cholesterol on removal of E2 by $\beta$-CDP

A solution of $10^{-9} \mathrm{~mol} / \mathrm{L}$ E2 was prepared and divided into six aliquots. Cholesterol was added to each aliquot to give cholesterol/E2 molar ratios of $0,0.1,1,10$, and $100 . \beta-C D P$ was added to each E2 solution at $0.2 \%(\mathrm{w} / \mathrm{v})$. Reference solutions were prepared without the addition of $\beta$-CDP. After $1 \mathrm{~h}$ incubation at room temperature, the solutions were centrifuged for $10 \mathrm{~min}$ at $3000 \mathrm{rpm}$. The E2 concentration in the supernatant was measured with E2 ELISA kit, and the 
removal ratio of $\mathrm{E} 2$ from each solution was calculated by comparing the treated solution to the reference.

2.5 Removal of dissolved estrogen from a municipal sewage plant effluent by $\beta$-CDP

Effluent of a municipal sewage treatment plant was obtained before chlorination and was filtered through GF/C (Whatman International Ltd., England). An E2 solution and mixture of E2 and cholesterol were prepared at $10^{-6} \mathrm{~mol} / \mathrm{L}$. $\beta$-CDP was added to these solutions at $0.2 \%(w / v)$. Reference was prepared without addition of $\beta$-CDP. After $1 \mathrm{~h}$ incubation at room temperature, the solutions were centrifuged for $10 \mathrm{~min}$ at $3000 \mathrm{rpm}$. The estrogenic activities of the supernatants were obtained by yeast two-hybrid assay and were converted into E2 concentrations. These assays were carried out by the Institute of Environment and Resource System Co., Ltd., which is the university-industry collaboration section of Yokohama National University (Yokohama, Japan). The removal ratio of E2 from each solution was calculated by comparing the treated solution to the reference.

3. Results and Discussions

\subsection{Adsorptive property of CDPs to E2}

E2 has an absorption maximum at $280 \mathrm{~nm}$ on a UV spectrum. The absorption intensity of the supernatant treated with each CDP decreased in the following order: $\beta$-CDP $\geq \gamma$-CDP 》 $\alpha-C D P$ (Fig. 1). This shows that these CDPs can remove E2 from waters. $\beta$-CDP was the most effective for removal of E2 from waters (Fig. 1). Oishi et al. (2008) previously showed that E2 selectively formed an inclusion complex with $\beta-C D$ or $\gamma-C D$ but not with $\alpha-C D$. In this study, $\beta$ - and $\gamma$-CDPs showed the highest selectivity for adsorption of $E 2$, similar to $\beta$ - and $\gamma^{-}$ 
CDs. Despite the fact that $\alpha-C D$ did not form a complex with E2, a-CDP adsorbed E2 as shown in Fig.1. This demonstrates that adsorption of E2 by $\alpha$-CDP is not due to a host-guest interaction through molecular recognition, but rather due to interaction with the polymer matrix. The mechanism for adsorption of E2 to $\beta$-CDP or $\gamma$-CDP is inclusion complex formation by selective incorporation into the hydrophobic cavity of a $\beta-C D$ molecule, nonselective incorporation into secondary cavities of the polymer network, and hydrogen bonding with linkers. Therefore, $\beta$ - and $\mathrm{y}$-CDPs are attractive material for the removal of E2 molecule from dissolved contaminants.

\subsection{Adsorption capacity of $\beta$-CDP to E2}

Estrogens affect reproduction and development in wildlife at the concentration of $\mathrm{ng} / \mathrm{L}$ order (Hansen et al., 1998; Jobling et al., 1998; Kolodziej et al., 2004; Metcalfe et al., 2001; Routledge et al., 1998). They were detected with concentrations ranging from $10^{-11}$ to $10^{-9}$ $\mathrm{mol} / \mathrm{L}$ in surface waters and dairy farm effluents (Sarmah et al., 2006; Velicu and Suri, 2009). Therefore, the removal efficiency of E2 by $\beta$-CDP was measured in the range of $10^{-11}$ to $10^{-8}$ molE2/L. The removal ratio was about $70 \%$ at $10^{-11}$ molE2/L and was more than $90 \%$ at $>10^{-10}$ molE2/L (Fig. 2). From these results, a high removal efficiency of E2 by $\beta$-CDP is expected over a wide range of estrogen concentrations.

\subsection{Effect of cholesterol on removal of estrogens by $\beta$-CDP}

Human and all other species of animals excrete different species of steroids. They are not only restricted to estrogen hormones but also originate from foods, medicines and their metabolites. Cleavage of the steroid ring barely occurs during the activated sludge treatment process. Therefore, different types and proportions of steroids including estrogens usually 
coexist in effluent of wastewater treatment plants. Cholesterols do not have estrogenic activity, but are able to form inclusion complexes with $\beta-C D$ (Kwak et al., 2002). In general, cholesterols were contained at higher concentrations than estrogens in wastewaters. Therefore, competition for adsorption to $\beta$-CDP may occur between estrogens and other steroids. E2 and cholesterol were selected as representatives of estrogens and other steroids, respectively. Figure 3 shows the removal ratio of E2 by $\beta$-CDP from solutions where the cholesterol/E2 molar ratios were $0,0.1,1,10$, and 100 . The removal ratio of E2 was lowest (about $85 \%$ ) at 100 molar ratio and $>90 \%$ at $0.1,1$, and 10 (Fig. 3 ). These results show that $\beta-C D P$ is able to remove low concentrations of $E 2$ in the presence of other steroids.

3.4 Removal of dissolved estrogen from a municipal sewage plant effluent by $\beta$-CDP

The estrogenic activity of this effluent corresponded to $5.5 \times 10^{-11}$ molE2 / $\mathrm{L}$ and were removed at $>90 \%$ by treatment with $\beta$-CDP (Table 1). On the other hand, the removal ratio of E2 from pure E2 solution of $10^{-11} \mathrm{~mol} / \mathrm{L}$ was about $70 \%$ (Fig. 2). The difference in these removal ratios is due to that in the assay methods. Estrogens of differing species and estrogenic activities can coexist in wastewaters. E2 is easily oxidized to E1 by microorganisms during an activated sludge treatment process. Estrogenic activity was the highest in E2, followed by E1 and E3. The activity of E2 is about 1.5-fold of E1 based on yeast two-hybrid assay (Jürgens et al., 2002). The effluent is also contaminated with synthetic estrogen analogs which are much more resistant to degradation than natural estrogens. Therefore, the concentration of estrogens in the effluent from a municipal sewage plant was estimated as that of E2 from determination of the estrogen activity using a yeast two-hybrid assay. The reference prepared with an $10^{-6} \mathrm{molE} 2 / \mathrm{L}$ was estimated to be $>0.765 \times 10^{-6}$ molE2/L by this assay (Table 1 ). This indicates that this assay is able to evaluate with the high reliability.

Cholesterol/E2 molar ratios of up to 100 did not affect to the removal efficiency of E2 by 
$\beta$-CDP (Fig. 3). In this yeast two-hybrid assay, $\beta$-CDP treatment also showed a high removal ratio of E2 in the presence of cholesterol (Table 1). From these results, $\beta$-CDP is able to remove a variety of steroids including estrogens over a wide range of concentrations. Figure 1 indicates that $\mathrm{\gamma}$-CDP has also the same removal capacity of steroid hormones as $\beta$-CDP.

\section{Conclusions}

$\beta$-CDP had a high capacity for removal of dissolved estrogens compared with $\alpha-C D P$. The mechanism for adsorption of estrogens to $\beta$-CDP was thought to be not only due to a host-guest interaction as molecular recognition by $\beta-C D$, but also due to the polymer matrix. When treated with $0.2 \%(\mathrm{w} / \mathrm{v}) \beta-\mathrm{CDP}$, the removal ratios of E2 were about $70 \%$ at $10^{-11}$ molE2/L and more than $90 \%$ at $\geq 10^{-10}$ molE2/L. When cholesterol and E2 were mixed at 0 , $0.1,1,10,100$ molar ratios, the removal of $\mathrm{E} 2$ was about $85 \%$ at 100 , and $>90 \%$ at $0.1,1$, and 10. The estrogenic activity of the effluent from a municipal sewage plant corresponded to $5.5 \times 10^{-11} \mathrm{molE} 2 / \mathrm{L}$ by yeast two-hybrid assay, and the treatment by $\beta$-CDP removed estrogens of $>90 \%$. Therefore, $\beta$-CDP has high adsorption capacity to estrogens in the coexistence of adsorptive competitors.

\section{Acknowledgments}

We thank Dr. T. Kikuchi of Aomori Prefectural Industrial Technology Research Center for providing $\alpha, \beta$, and $\gamma$-CDPs. 


\section{References}

Belfroid AC, Van der Horst A, Vethaak AD, Schäfer A J, Rijs G B J, Wegener J, Cofino W P. Analysis and occurrence of estrogenic hormones and their glucuronides in surface water and waste water in The Netherlands. Sci Total Environ 1999; 225: 101-108.

Cathum SJ, Boudreau A, Obenauf A, Dumouchel A, Brown CE, Punt M. Treatment of mixed contamination in water using cyclodextrin-based materials. Remediation J 2006; 16: 43-56.

Chimchirian RF, Suri RPS, Fu H. Free synthetic and natural estrogen hormones in influent and effluent of three municipal wastewater treatment plants. Water Environ Res 2007; 79: 969-974.

Desbrow C, Routledge EJ, Brighty GC, Sumpter JP, Waldock M. Identification of estrogenic chemicals in STW effluent: 1. Chemical fractionation and in vitro biological screening. Environ Sci Technol 1998; 32: 1549-1558.

Hanselman TA, Graetz DA, Wilkie AC. Manure-borne estrogens as potential environmental contaminants. A review. Environ Sci Technol 2003; 37: 5471-5478.

Hansen P, Dizer H, Hock B, Marx A, Sherry J, McMaster M, Blaise Ch. Vitellogenin- a biomarker for endocrine disruptors. Trends Anal Chem 1998; 17: 448-451.

Holbrook RD, Novak JT, Grizzard TJ, Love N G. Estrone receptor agonist fate during wastewater and biosolids treatment processes: A mass balance analysis. Environ Sci Technol 2002; 36: 4533-4539.

Hunag C, Sedlak D. Analysis of estrogenic hormones in municipal wastewater effluent and surface waters using enzyme linked immunosorbent assay and gas chromatography/tandem mass spectrometry. Environ Toxicol Chem 2001; 20: 133-139.

Isobe T, Shiraishi H, Yasuda M, Shinoda A, Suzuki H, Morita M. Determination of estrogens and their conjugates in water using solid-phase extraction followed by liquid chromatography-tandem mass spectrometry. J Chromatogr 2003.; A 984: 195-202.

Johnson AC, Belfroid A, Corcia A Di. Estimating steroid estrogen inputs to activated sludge treatment works and observations on their removal from effluent. Sci Total Environ 2000; 256:163-173.

Jobling S, Nolan M, Tyler C, Brighty G, Sumpter J. Widespread sexual distribution in wild 
Jürgens MD, Holthaus KI E, Johnson A C, Smith JJL, Hetheridge M, Williams R J. The potential for estradiol and ethinylestradiol degradation in English rivers. Environ Toxicol Chem 2002; 21: 480-488.

Kikuchi T, Kondo Y, Hamada F. Synthesis of endocrine disruptor absorbent based on cyclodextrin. Int J Soc Mater Eng Resour 2005; 13: 13-16.

Kolodziej EP, Harter T, Sedlak D L. Dairy wastewater, aquaculture, and spawning fish as sources of steroid hormones in the aquatic environment. Environ Sci Technol 2004; 38: 6377-6384.

Kömer W, Spengler P, Bolz U, Schuller W, Hanf V, Metzger J. Substances with estrogenic activity in effluent of sewage treatment plants in southwestern Germany: 2. Biological analysis. Environ Toxicol Chem 2001; 20: 2142-2151.

Kozlowski CA, Girek T, Walkowiak W., Koziol JJ. Application of hydrophobic $\beta$-cyclodextrin polymer in separation of metal ions by plasticized membranes. Sep Purif Technol 2005; 46: 136-144.

Kwak HS, Jung CS, Shim S Y, Ahn J. Removal of cholesterol from cheddar cheese by ß-cyclodextrin. J Agric Food Chem 2002; 50: 7293-7298.

Metcalfe C D, Metcalfe T L, Kiparissis Y, Koenig BG, Khan C, Hughes RJ, Croley TR, March RE, Potter T. Estrogenic potency of chemicals detected in sewage treatment plant effluents as determined by in vivo assay with Japanese medaka (Oryzias latipes). Environ Toxicol Chem 2001; 20: 297-308.

Miles-Richardson S R, Kramer VJ, Fitzgerald S D, Render JA, Yamini B, Barbee SJ, Giesy JP. Effects of waterborne exposure of 17-estradiol on secondary sex characteristics and gonads of fathead minnows (Pimephales promelas). Aquat Toxicol 1999; 47: 129-145.

Murai S, Imajo S, Takasu Y, Takahashi K, Hattori K. Removal of phthalic acid esters from aqueous solution by inclusion and adsorption on $\beta$-cyclodextrin. Environ Sci Technol 1998; 32: 782-787.

Oishi K, Toyao K, Kawano Y. Suppression of estrogenic activity of $17 \beta$-estradiol by $\beta$-cyclodextrin. Chemosphere 2008; 73:1788-1792. 
Panter GH, Thompson RS, Sumpter JP. Adverse reproductive effects in male fathead minnows (Pimephales promelas) exposed to environmentally relevant concentrations of the natural oestrogens, oestradiol and oestrone. Aquat. Toxicol 1998; 42: 243-253.

Rodgers-Gray T, Jobling S, Morris S, Kelly C, Kirby S, Janbakhsh A, Harries J, Waldock M, Sumpter J, Tyler C. Long-term temporal changes in the estrogenic composition of treated sewage effluent and its biological effects on fish. Environ Sci Technol 2000; 34: 1521-1528.

Routledge EJ, Sheahan D, Desbrow C, Brightly GC, Waldock M, Sumter JP. Identification of estrogenic chemicals in STW. 2. In vivo responses in trout and roach. Environ Sci Technol 1998; 32: 1559-1565.

Sarmah AK, Northcott G.L, Leusch FD L, Tremblay LA. A survey of endocrine chemicals (EDCs) in municipal sewage and animal waste effluents in the Waiko region of New Zealand. Sci Total Environ 2006; 355:135-144.

Samir KK, Xie B, Thompson ML, Sung S, Ong SK, Hans Van Leeuwen J. Fate, transport, and biodegradation of natural estrogens in the environment and engineered systems. Environ Sci Technol 2006; 40: 6537-6546.

Shore L, Shemesh M. Naturally produced steroid hormones and their release into the environment. Pure Appl Chem 2003; 75: 1859-1871.

Snyder S, Villeneuve D, Snyder E, Giesy J. Identification and quantification of estrogen receptor agonists in wastewater effluents. Environ Sci Technol 2001; 35: 3620-3625.

Velicu M, Suri R. Presence of steroid hormones and antibiotics in surface water of agricultural, suburban and mixed-use areas. Environ Monit Assess 2009; 154: 349-359. 


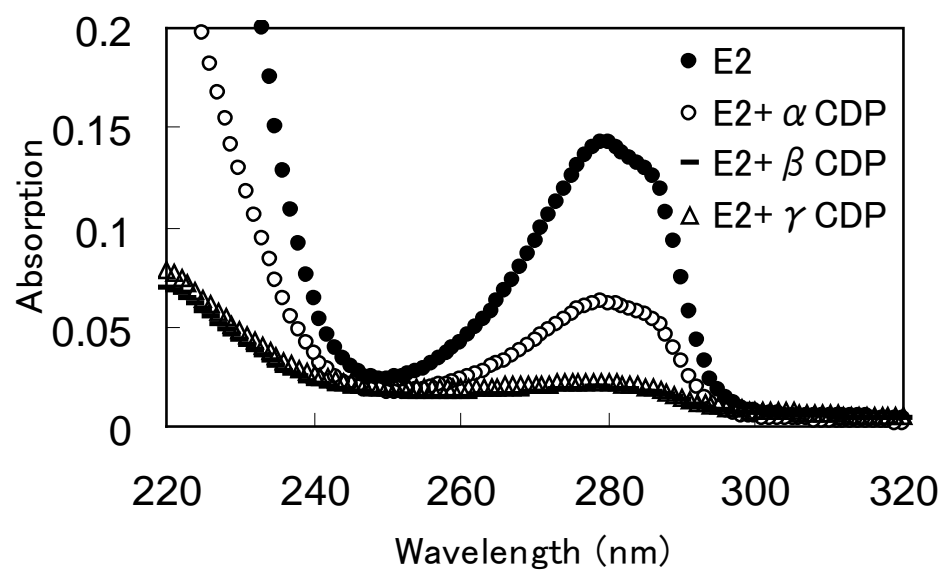

Fig.1 UV spectrum of E2 in the presence of $\alpha-, \beta-$, and $\gamma^{-C D P s}$ 


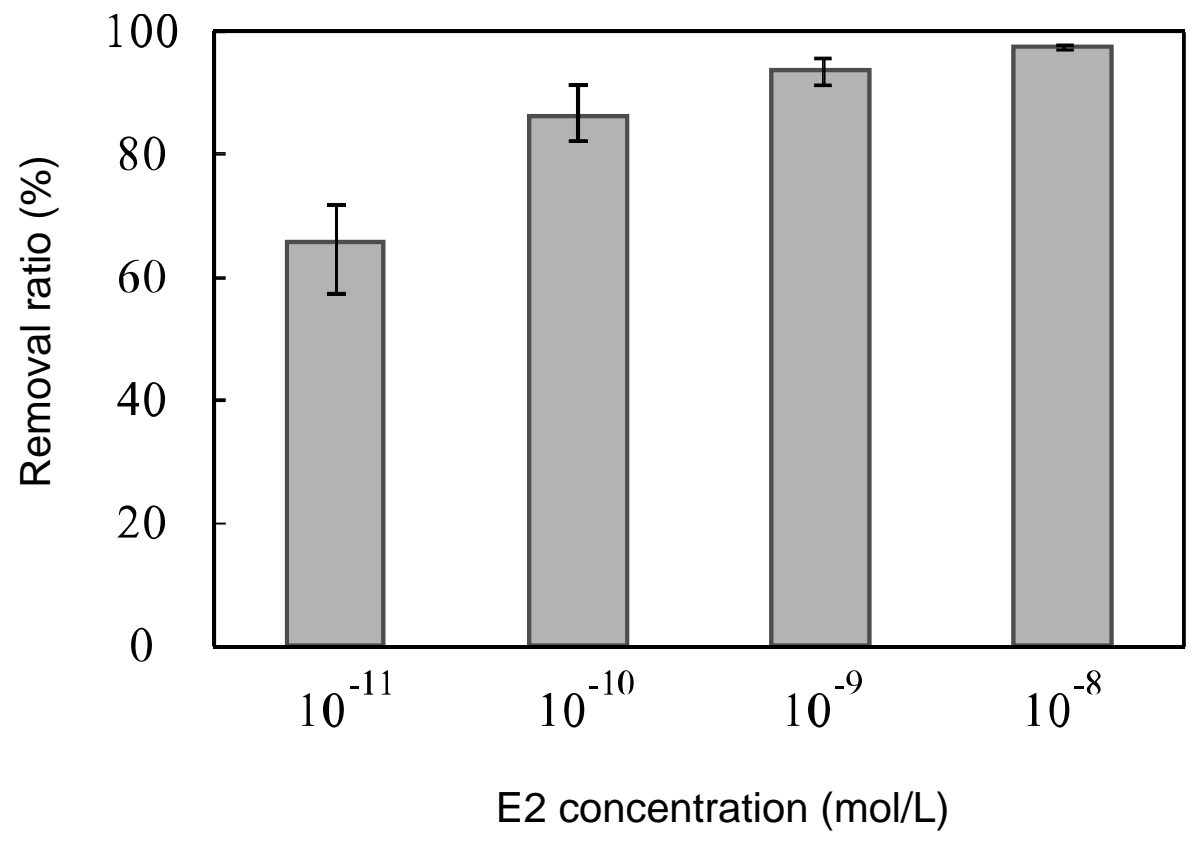

Fig.2 Removal ratios of E2 by $\beta$-CDP from different dilute E2 solution 


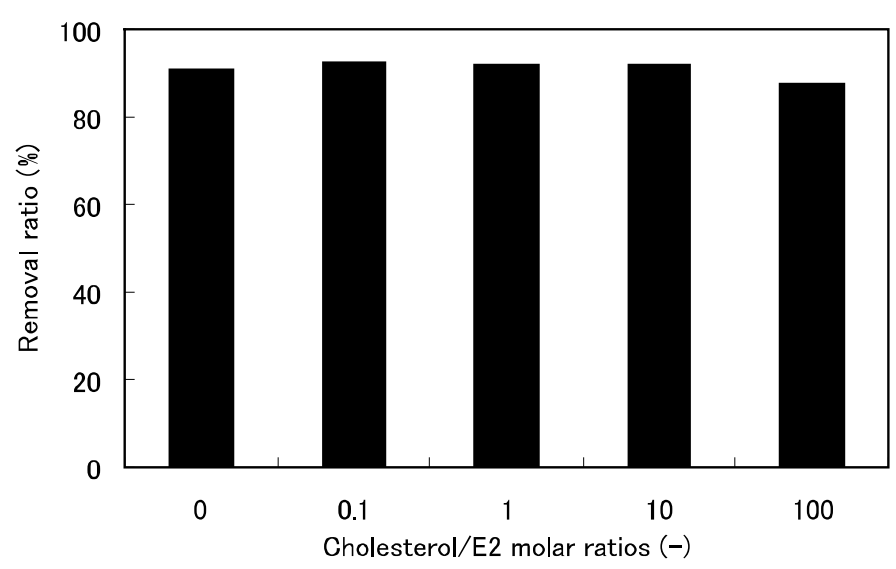

Fig.3 Effects of cholesterol to removal of E2 by $\beta$-CDP 
Table 1 Removal of dissolved estrogen by $\beta$-CDP from a wastewater treatment effluent

\begin{tabular}{l|ccc}
\hline Sample & $\beta-\operatorname{CDP}(\%)$ & E2 $^{*}\left(10^{-9} \mathrm{~mol} / \mathrm{L}\right)$ & Removal ratio (\%) \\
\hline \hline $10^{-6} \mathrm{E} 2 \mathrm{~mol} / \mathrm{L}$ & - & 767 & - \\
\multirow{2}{*}{$10^{-6} \mathrm{E} 2+$ Cholesterol $\mathrm{mol} / \mathrm{L}$} & 0.2 & 40 & 94.8 \\
\hline \multirow{2}{*}{ Effluent form sewage work } & 0.2 & 38.9 & 94.9 \\
& - & 0.055 & - \\
& 0.2 & $<0.004$ & $>91.9$ \\
\hline
\end{tabular}

*The value was estimated as E2 from estrogenic activity of yeast two hybrid assay 